\title{
Evaluation of the dentists' knowledge on medical urgency and emergency
}

\section{Tássia Carina STAFUZZA(a) Cleide Felício Carvalho CARRARA ${ }^{(a)}$}

Fernanda Veronese OLIVEIRA(b)

Carlos Ferreira SANTOS(c)

Thais Marchini OLIVEIRA(b)

(a) Hospital for Rehabilitation of Craniofacial Anomalies, University of São Paulo - USP, Bauru, SP, Brazil.

(b)Department of Pediatric Dentistry, Orthodontics and Community Health, Bauru School of Dentistry, University of São Paulo USP, Bauru, SP, Brazil.

(c)Department of Biological Sciences, Bauru School of Dentistry, University of São Paulo USP, Bauru, SP, Brazil

Declaration of Interests: The authors certify that they have no commercial or associative interest that represents a conflict of interest in connection with the manuscript.

DOI: 10.1590/1807-3107BOR-2014.vol28.0029 Epub Xxx XX, 2014

Submitted: Dec 19, 2013

Accepted for publication: Apr 14, 2014

Last revision: Jul 11,2014
Abstract: This study aimed at evaluating how well dentists understand medical emergency/urgency procedures and issues during dental treatment at a hospital specialized in cleft lip and palate. It comprised a hundred dentists from the Hospital for Rehabilitation of Craniofacial Anomalies, University of São Paulo (HRAC/USP), Brazil, from different dental specialties. A questionnaire was applied to evaluate their knowledge of medical emergencies/urgencies from June through September 2011. The questionnaire was anonymous, confidential and constructed with closed questions and either yes-no or multiple-choice responses. Results showed that most professionals ( $87 \%$ ) were trained in basic life support (BLS), but only $43 \%$ considered themselves capable of providing first aid and performing the necessary maneuvers. Most participants (94\%) claimed that they knew the difference between medical urgencies and emergencies, and 69\% had BLS training in their undergraduate courses, as opposed to $37 \%$, during their specialization. Some participants $(23 \%)$ mentioned that they had received knowledge of the subject during extracurricular courses and/or graduate courses (12\%). Only 9\% had not been educated on the subject; however, all participants showed interest in attending a course in BLS. In regard to assessing training that dentists who attended BLS courses received, 49\% were satisfied and $42 \%$ were dissatisfied. Results of the present study emphasize that dentists from HRAC/USP have little knowledge about BLS procedures to perform them. Dentists must gain adequate education and training to minimize possible technical, ethical and legal problems associated with dental practice. It is necessary to improve both knowledge and practice in order to become well-qualified practitioners.

Keywords: Medicine; Emergency Relief; Hospitals.

\section{Introduction}

During their practice, dentists face the risk of coming face-to-face with emergency events, especially medical emergencies. These emergencies should be treated immediately, and cannot be avoided or referred, because they put the life and health of patients at risk, and cause emotional stress to the professionals involved. The occurrence of emergency and urgency episodes during out-patient treatment is unpredictable and does not always follow set patterns, but few dentists are prepared to face these episodes, because they lack the appropriate knowledge. ${ }^{1,2,3,4}$

The curriculum of undergraduate dentistry courses lacks either disciplines or contents, both of which are needed for emergency and/or 
urgency situations, as well as for training undergraduates to perform actions related to such intercurrences. ${ }^{5}$ Usually, Cardiopulmonary Resuscitation is taught to dentistry undergraduates in the disciplines of Oral and Maxillofacial Surgery and Traumatology. ${ }^{6}$ However, many of these undergraduates do not have the opportunity of assimilating or performing the procedures correctly, either during the course or in their professional life. In addition, dentists are not aware or prepared enough to equip their offices with what is required for emergency/ urgency care; therefore, they are at a loss even before such situations may occur. $3,7,8,9,10$

It is difficult to find a dentist who feels capable of correctly treating emergencies and/or urgencies that may occur during out-patient treatment, because this issue is discussed only superficially in many undergraduate courses. ${ }^{8}$ Regardless of the severity or type of the emergency/urgency, it is recommended that the dentist be able and feel safe enough to manage Basic Life Support (BLS), know whom to ask for help, and be trained to perform it, in addition to knowing how to deal with emergency equipment. ${ }^{11}$ Therefore, the aim of this study was to evaluate how well dentists understand medical emergency/urgency procedures and issues during dental treatment at a hospital specialized in cleft lip and palate.

\section{Methodology}

Following ethical and legal guidelines, this research was submitted to the Ethical Committee in Human Research of the Hospital for Rehabilitation of Craniofacial Anomalies, University of São Paulo (HRAC/ USP), protocol number \#61/2011), and the procedures started after the approval and signing of a free and informed consent form by the participants.

A questionnaire was applied to evaluate the level of knowledge of dentists regarding medical emergencies/urgencies from June through September 2011. The questionnaire was anonymous and confidential, and was constructed with closed questions and either yes-no or multiple-choice responses. The questionnaire characterized the sample in regard to age, gender, time since graduation, titles, and questions regarding attendance of BSL courses, through an interview guide containing a predetermined set of questions that served as a checklist to determine the level of knowledge of dentists regarding medical emergency/urgency procedures. The dentists were advised to answer the questions without resorting to literary material or other professionals. The sample was composed of 127 dentists who comprised the Dentistry Center staff of the HRAC/USP from different dental specialties. A hundred dentists agreed to participate in the study. All dentists were informed about the study and all of their informed consents were obtained. According to a prior study by Laurent et al. ${ }^{6} 2009$, a sample size of 100 dentists was calculated to obtain a power of $80 \%$ and a significance level of $5 \%$.

\section{Results}

Of the 100 dentists who participated in the study at the Dentistry Center of the HRAC/USP, 73\% were female and $27 \%$ male. The most common age range was 20 to 30 years old $(80 \%)$. The most prevalent response for time since graduation was from 0 to 5 years $(75 \%)$; this was probably because all of the respondents were students of the hospital's graduate courses.

Most of the participants (94\%) affirmed that they knew the difference between medical urgencies and emergencies, and $87 \%$ of them said they had training in BLS, provided in their undergraduate studies (69\%) and/or specialization (37\%) courses. Some participants $(23 \%)$ mentioned that they had received knowledge of the subject during extracurricular courses and/ or graduate courses $(12 \%)$. Only $9 \%$ did not receive any knowledge of the subject; however, all participants showed interest in attending a course in BLS. In regard to the dentists who attended BLS courses, $49 \%$ were satisfied and $42 \%$ were dissatisfied with the training they had received.

Most of the participants showed enough knowledge to diagnose a medical emergency/urgency $(66 \%)$, but not all of them felt able to perform first aid and BLS maneuvers (57\%). A small percentage of the respondents (28\%) knew how to handle the emergency equipment properly, and $67 \%$ were prepared to perform cardiopulmonary resuscitation (Table 1).

When asked whether the HRAC/USP had any agreement with a medical service for patient removal, $81 \%$ claimed to be unaware of any such agreement. Few 
Table 1. Extent of BLS training of the dentists interviewed at the Hospital for Rehabilitation of Craniofacial Anomalies

\begin{tabular}{lcc}
\hline Questionnaire & Positive response (\%) & Negative response (\%) \\
\hline Do you know how to diagnose medical urgencies and emergencies? & $66 \%$ & $34 \%$ \\
Do you know how to perform BLS and first-aid? & $43 \%$ & $57 \%$ \\
Do you know how to handle the equipment? & $28 \%$ & $72 \%$ \\
Do you know how to perform cardiopulmonary resuscitation? & $67 \%$ & $33 \%$ \\
\hline
\end{tabular}

participants (22\%) responded that they were present in any case of an emergency/urgency at the hospital.

The dentists (87\%) affirmed that they had a legal obligation to rescue patients; however, $8 \%$ were aware of the law stating this, and only $9 \%$ were aware of any law that supports dentists acting to help the patient. Many participants (99\%) agreed that to rescue a patient in the case of an emergency/urgency does not represent practicing medicine illegally. Of these, $98 \%$ stated that the dentist, and not the doctor, is responsible for a patient in an emergency/urgency situation in a dental environment. The dentists (81\%) answered that when they do not perform first aid procedures, they commit the crime of omission of help. For many participants (70\%), dentists are not obliged to provide first aid in a dental environment (Table 2).

Table 2. Extent of ethical and legal implications of the dentists interviewed at the Hospital for Rehabilitation of Craniofacial Anomalies

\begin{tabular}{lcc}
\hline Questionnaire & $\begin{array}{c}\text { Positive } \\
\text { response } \\
(\%)\end{array}$ & $\begin{array}{c}\text { Negative } \\
\text { response } \\
(\%)\end{array}$ \\
\hline $\begin{array}{l}\text { Are dentists obliged by law to provide } \\
\text { first aid? }\end{array}$ & $87 \%$ & $13 \%$ \\
$\begin{array}{l}\text { Do you know what law this is? } \\
\quad \text { 13\% did not answer since their } \\
\text { response was "no" to the previous } \\
\text { question. }\end{array}$ & $8 \%$ & $79 \%$ \\
$\begin{array}{l}\text { Do you know any law that supports the } \\
\text { dentist? } \\
\text { If a dentist rescues a patient, will he/she } \\
\text { be performing medicine illegally? } \\
\begin{array}{l}\text { Could dentists commit the crime of } \\
\text { omission? }\end{array}\end{array}$ & $9 \%$ & $81 \%$ \\
$\begin{array}{l}\text { Are dentists obliged to provide first aid } \\
\text { only within the dental environment? }\end{array}$ & $81 \%$ & $19 \%$ \\
\hline
\end{tabular}

\section{Discussion}

Medical urgencies and emergencies may occur with any person, at any time and place, as well as during and after any dental procedure. A general health evaluation of patients demanding special care and the adoption of preventive measures increase the clinical safety of treatments for these patients. ${ }^{79,11}$

An emergency may be defined as a situation occurring mostly due to disease, anxiety or complications during treatment, all of which may put the patient's life at risk. On the other hand, urgency is defined as a condition where there is no significant risk to the patient's life ${ }^{12}$ Nevertheless, immediate management is of fundamental importance in both cases. An important consideration is BLS, or the $A B C$ 's of life support, consisting of opening the (A) airways, good (B) breathing, and (C) circulation. . $^{13,14}$

The main emergency situations may be summarized as: drug allergy, acute myocardial infarction, cardiac arrest, respiratory arrest and anaphylactic shock. In regard to the urgencies during dentistry practice, these may include syncope (fainting), hyperventilation, asthma attacks, hypertensive crises, seizure and angina pectoris. ${ }^{13}$

As health professionals, dentists must be aware that they are dealing with human life, and must consequently assume the risks and responsibilities inherent to their occupation. In Brazil, according to the Code of Consumer Protection and Defense (CCPD), the dentist is considered a supplier of services and has the obligation to be well-prepared to offer a service to the patient. $\mathrm{He}$ is responsible (regardless of the existence of guilt) for compensating any damage caused to a consumer, related to both poor services and insufficient or inadequate information on the provision and risks of these services. It is important to note that the dentist's performance is regulated by the Brazilian Code of Ethics, stipulating that fundamental rights and duties should underlie and guide several aspects of the dentist's professional life. Thus, dentists should seek adequate professional training to minimize the ethical and legal problems that may arise during their practice. ${ }^{1,9,1,15}$

BLS training is fundamental to health area professionals. In this study, $87 \%$ of the dentists interviewed asserted that they had received training, but only $43 \%$ 
were aware of having treated any urgency or emergency. These data deserve attention, because half of the hospital staff felt prepared to manage these cases. In this sense, Brazilian Law \#5081/6623 regulates the dentistry practice and states that dentists are obliged "to prescribe and apply urgency medication in cases of severe accidents compromising the patient's life and health." Furthermore, the Brazilian Dentistry Code of Ethics states that it is an obligation "to ensure the patient's health and dignity."

The data obtained in this study are similar to those reported in other studies, concluding that dentists are

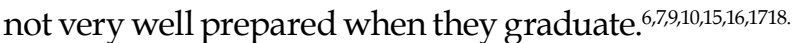
Chapman, ${ }^{7}$ 1995, reported that little information has been published on the level of knowledge of emergency/urgency procedures and the perceived competence of dentists in resuscitation procedures, or on resuscitation emergencies that occur in dental practice. Arsati et al., ${ }^{9}$ 2010, demonstrated that Brazilian dentists are not fully prepared to manage medical emergencies and have insufficient experience and training in cardiopulmonary resuscitation. Skapetis et al.,16 2011, suggested that medical practitioners have little education and training to deal with dental emergencies. In contrast, Müller et al. ${ }^{15}, 2008$, found that medical emergencies are not rare in dental practice, although most are not life-threatening. Improvement of emergency management skills should include repeated attendance of life support courses, standardization of courses and offering courses designed to meet the needs of dentists. Gupta et al., 2008 , asserted that the training of practic-

\section{References}

1. Gonzaga HF, Buso L, Jorge MA, Gonzaga LH, Chaves MD, Almeida OP. Evaluation of knowledge and experience of dentists of São Paulo State, Brazil about cardiopulmonary resuscitation. Braz Dent J. 2003;14(3):220-2.

2. Wilson MH, McArdle NS, Fitzpatrick JJ, Stassen LF. Medical emergencies in dental practice. J Ir Dent Assoc. 2009 JunJul;55(3):134-43.

3. Sopka S, Biermann H, Druener S, Skorning M, Knops A, Fitzner $\mathrm{C}$, et al. Practical skills training influences knowledge and attitude of dental students towards emergency medical care. Eur J Dent Educ. 2012 Aug;16(3):179-86.

4. Gupta T, Aradhya MR, Nagaraj A. Preparedness for management of medical emergencies among dentists in Udupi and Mangalore, India. J Contemp Dent Pract. 2008 Jul 1;9(5):92-9. ing dentists in medical emergency management must be improved on the undergraduate, graduate and continuing education level, and that the dental workplace must be organized to handle such emergencies.

Considering the aforementioned discussion, the present study alerts the dentistry community at the HRAC/USP to the possibility of medical emergencies and urgencies occurring in dental offices, and to securing more rigorous involvement at undergraduate, graduate and continuing education levels. An effective interactive workshop employing several different instructional techniques could help improve the management of dental emergencies and patient outcomes. ${ }^{19}$ This study shows that, according to the sample studied, there is a significant gap in dental education that may be occurring countrywide. New investigations and changes in the training of dentists to improve their knowledge of medical emergency/ urgency procedures and issues are suggested.

\section{Conclusion}

The results of the study emphasize that the dentists from the HRAC/USP have little knowledge to perform Basic Life Support procedures adequately. Dentists must gain more adequate education and training to minimize possible technical, ethical and legal problems associated with dental practice. It is necessary to improve both knowledge and practice in order to become well-qualified practitioners.

5. Greenwood M, Beattie A, Green R, Durham J. Aspects of training in clinical medical sciences in dentistry (human disease): recent graduates' perspectives from a UK dental school. Eur J Dent Educ. 2013 May;17(2):114-21.

6. Laurent F, Augustin P, Nabet C, Ackers S, Zamaroczy D, Maman L. Managing a cardiac arrest: evaluation of final-year predoctoral dental students. J Dent Educ. 2009 Feb;73(2):211-7.

7. Chapman PJ. A questionnaire survey of dentists regarding knowledge and perceived competence in resuscitation and occurrence of resuscitation emergencies. Aust Dent J. 1995 Apr;40(2):98-103.

8. Adewole RA, Sote EO, Oke DA, Agbelusi AG. An assessment of the competence and experience of dentists with the management of medical emergencies in a Nigerian teaching hospital. Nig Q J Hosp Med. 2009 Sep-Dec;19(4):190-4 
9. Arsati F, Montalli VA, Flório FM, Ramacciato JC, Cunha FL, Cecanho R, et al. Brazilian dentists' attitudes about medical emergencies during dental treatment. J Dent Educ. 2010 Jun;74(6):661-6.

10. Carvalho RM, Costa LR, Marcelo VC. Brazilian dental students' perceptions about medical emergencies: a qualitative exploratory study. J Dent Educ. 2008 Nov;72(11):1343-9.

11. Atherton GJ, Pemberton MN, Thornhill MH. Medical emergencies: the experience of staff of a UK dental teaching hospital. Br Dent J. 2000 Mar 25;188(6):320-4.

12. Broadbent JM, Thomson WM. The readiness of New Zealand general dental practitioners for medical emergencies. N Z Dent J. 2001 Sep;97(429):82-6.

13. Fukayama H, Yagiela JA. Monitoring of vital signs during dental care. Int Dent J. 2006 Apr;56(2):102-8.

14. Spencer B, Chacko J, Sallee D; American Heart Association. The 2010 American Heart Association guidelines for cardiopulmonary resuscitation and emergency cardiac care: an overview of the changes to pediatric basic and advanced life support. Crit Care Nurs Clin North Am. 2011 Jun;23(2):303-10.
15. Müller MP, Hänsel M, Stehr SN, Weber S, Koch T. A statewide survey of medical emergency management in dental practices: incidence of emergencies and training experience. Emerg Med J. 2008 May;25(5):296-300.

16. Skapetis T, Gerzina T, Hu W. Management of dental emergencies by medical practitioners: recommendations for Australian education and training. Emerg Med Australas. 2011 Apr;23(2):142-52.

17. McCann PJ, Sweeney MP, Gibson J, Bagg J. Training in oral disease, diagnosis and treatment for medical students and doctors in the United Kingdom. Br J Oral Maxillofac Surg. 2005 Feb;43(1):61-4.

18. Girdler NM, Smith DG. Prevalence of emergency events in British dental practice and emergency management skills of British dentists. Resuscitation. 1999 Jul;41(2):159-67.

19. Skapetis T, Gerzina T, Hu W. Can a four-hour interactive workshop on the management of dental emergencies be effective in improving self reported levels of clinician proficiency? Australas Emerg Nurs J. 2012 Feb;15(1):14-22. 